\title{
Pedagogia de projetos e direitos humanos: caminhos para uma educação em valores
}

\author{
Ulisses Ferreira de Araújo *
}

Resumo: Este artigo apresenta as discussóes e os resultados parciais de uma pesquisa longitudinal desenvolvida durante quatro anos em uma escola de ensino fundamental. Seu objetivo era investigar se o trabalho com projetos, utilizando a Declaração Universal dos Direitos Humanos como referência, poderia se mostrar como um bom instrumento para a reorganização dos espaços, dos tempos e das relaçóes escolares, auxiliando na formação ética dos estudantes. Como resultado do trabalho, além da descrição de estratégias de ação e da sistematização dos procedimentos que podem levar as escolas à implementação de tal proposta, conseguimos demonstrar como um trabalho sistematizado de educação em valores éticos e democráticos pode levar a uma maior consciência ética e sócio-política.

Palavras-chave: Pedagogia de projetos; educação em valores; direitos humanos.

\section{Human rights and project pedagogy: ways for education on values}

Abstract: This article presents the discussions and partial results of a four-year longitudinal research, developed in a Brazilian elementary school. The main goal was to investigate if a project-based curriculum, using the Universal Declaration of Human Rights as a reference, could help the school to reorganize its spaces, times and relationships, contributing to students' ethical development. As a result, besides the description of strategies and the systematization of procedures that may lead schools to succeed in implementing such proposal, we have demonstrated how an educational process based on values can help students to develop greater ethical and sociopolitical consciousness.

Key words: project-based curriculum; education on values; human rights.

\section{Introdução}

Este artigo apresenta as discussôes e os resultados parciais de uma pesquisa longitudinal que desenvolvi durante quatro anos em uma instituição educacional da cidade de Campinas, em São Paulo: a Escola Comunitária de Campinas.

* Professor livre-docente da Escola de Artes, Ciências e Humanidades, Universidade de São Paulo (USP).Brasil.uliarau@usp.br 
Na pesquisa que ora apresento, definimos que o trabalho com projetos, na perspectiva do planejamento em "rede", utilizando a Declaração Universal dos Direitos Humanos como referência, poderia se mostrar poderosa na reorganização dos espaços, dos tempos e das relações escolares, podendo auxiliar na formação ética de quem os experienciasse de forma articulada.

A implementação desse trabalho ocorreu de forma gradual entre os anos de 2001 e 2005 , sendo que de 2001 a 2003 a escola contou com minha assessoria e supervisão direta. Posteriormente, o trabalho foi acompanhado por orientandos de mestrado e de doutorado.

Meu objetivo com essa pesquisa foi, principalmente, desenvolver as estratégias de ação e a sistematização dos procedimentos que podem levar as escolas à implementação de projetos nesta perspectiva. Por isso, o objetivo não foi tanto o de coletar dados que comprovassem possíveis êxitos (apesar de termos coletado tais dados), e sim o de desenvolver procedimentos.

\section{O construtivismo como opção teórica e epistemológica}

A construção dos conhecimentos, na forma como a concebemos, pressupõe um sujeito ativo, que participa de maneira intensa e reflexiva das aulas. Pressupõe um sujeito que constrói sua inteligência e sua identidade, através do diálogo estabelecido com seus pares, com os professores e com a cultura, na própria realidade cotidiana do mundo em que vive. Estamos falando, portanto, de alunos e alunas que são autores do conhecimento, e não meros reprodutores daquilo que a sociedade decide que devam aprender. No fundo, estamos falando de uma proposta educativa que promova a aventura intelectual e, acredito, a concepção construtivista é a mais adequada para atingir tais objetivos. Assumir o construtivismo como uma aventura do conhecimento pressupóe dar voz aos estudantes, promover o diálogo, incitar-lhes a curiosidade, levá-los a questionar a vida cotidiana e os conhecimentos científicos e, acima de tudo, darlhes condiçóes para que encontrem as respostas para suas próprias perguntas, tanto do ponto de vista individual quanto do coletivo.

Com esta discussão, quero trazer à tona um detalhe nos caminhos de compreensão da transversalidade, que são a base desses projetos de intervenção educativa. O caminho construtivista fornece a chave que permite articular os conhecimentos científicos e os saberes populares e cotidianos, propiciando condiçôes para que os questionamentos científicos sejam respondidos à luz das curiosidades dos alunos, em suas necessidades e interesses. De maneira específica, o construtivismo, ao reconhecer o papel ativo e autoral de alunos e alunas

Utilizando a metáfora das redes neurais como referência. 
na construção e na constituição de suas identidades e de seus conhecimentos, coloca os sujeitos da educação no centro do processo de ensino-aprendizagem. Se quisermos, de fato, promover a formação ética e para a cidadania, a partir da introdução de temáticas que objetivem a educação em valores, que tentem responder aos problemas sociais, e conectar a escola com a vida das pessoas, podemos assumir a epistemologia construtivista como referencial para a construção das práticas da transversalidade.

\section{O ensino transversal}

Como trabalhar a transversalidade e os temas transversais na sala de aula? $\mathrm{Na}$ concepção que adotamos, as temáticas transversais são o eixo vertebrador do sistema educacional, sua própria finalidade. Nela, na concepção de transversalidade que adotamos, os conteúdos tradicionais da escola deixam de ser a "finalidade" da educação e passam a ser concebidos como "meio", como instrumentos para trabalhar os temas que constituem o centro das preocupaçôes sociais. Entendemos que se esses conteúdos (tradicionais) estruturam-se em torno de eixos que exprimem a problemática cotidiana atual e que, inclusive, podem constituir finalidades em si mesmos, convertem-se em instrumentos cujo valor e utilidade são evidenciados pelos alunos e pelas alunas (Moreno,1997, p.38).

Assim, as temáticas que objetivam a educação em valores, que tentam responder aos problemas sociais, e conectar a escola com a vida das pessoas, transformam-se no eixo vertebrador do sistema educativo, em torno do qual serão trabalhados os conteúdos curriculares tradicionais.

Essa concepção, para muitos chamada de radical, muda o foco e o próprio objetivo da educação, pressupóe uma maneira totalmente diferente de encarar o ensino. O eixo de formação ética para a cidadania passa a ser a principal finalidade da educação. A educação em valores, a preocupação com o ensino de formas dialógicas e democráticas de resolução dos conflitos cotidianos e dos problemas sociais e a busca de articulação entre os conhecimentos populares e os conhecimentos científicos, dão um novo sentido à escola.

Os temas cotidianos e os saberes populares passam a ser ponto de partida - e muitas vezes também de chegada - para as aprendizagens escolares, dando um novo sentido e significado para os conteúdos científicos e culturais que a escola trabalha.

Procurando trazer situaçôes concretas para ilustrar o que propomos, o problema de poluição do córrego que passa no meio de uma favela, por exemplo, pode ser o eixo em torno do qual serão desenvolvidos os trabalhos na escola que atende aquela comunidade. Os conhecimentos matemáticos, a Língua Portu- 
guesa, a História, a Geografia, os diversos conteúdos de Ciências, as atividades de Educação Artística, serão desenvolvidos com o objetivo de levar as crianças que ali vivem a: tomar consciência das causas da poluição; conhecer a história da ocupação daquele local pelo ser humano; buscar o conhecimento de todos os agentes sociais envolvidos com o problema e suas responsabilidades sociais e éticas; avaliar as consequiências para a saúde das pessoas e para o meio ambiente; procurar caminhos sociais e políticos para a resolução do problema e para a melhoria da qualidade de vida das pessoas, etc.

Da mesma forma, os problemas de violência em uma escola, ou na comunidade próxima, podem ser o ponto de partida para a organização do planejamento curricular durante um determinado período de tempo. Com isso, as produçốes de textos, as pesquisas sobre dados estatísticos e as causas sociais e históricas da violência, o estudo do corpo humano, seriam relacionados: à compreensão dos sentimentos dos diferentes atores envolvidos em questôes de violência; à procura por caminhos dialógicos e democráticos de resolução de conflitos; aos estudos sobre questôes de gênero e à questão da violência doméstica; ao papel do desemprego ou do egocentrismo na geração da violência, etc.

E, ainda, os conflitos envolvendo a sexualidade adolescente podem ser a base de um projeto bimestral, envolvendo todos os professores. As leituras de livros de literatura, o trabalho com as regras gramaticais da língua, os conteúdos de Ciências relacionados ao desenvolvimento do corpo e da reprodução humana, a construção social e histórica da sexualidade, as diferenças culturais da sexualidade nos diversos países, os conteúdos de Economia e Matemática são exemplos de conteúdos científicos e culturais que poderiam ser pensados como "meio", como instrumento, para: a tomada de consciência dos sentimentos e emoçôes das pessoas em relação ao próprio corpo; o consumismo e o papel da mídia no estabelecimento de padróes de beleza; os problemas éticos decorrentes dos estigmas e preconceitos estabelecidos a partir das diferenças de valores; as DSTs e sua prevenção, etc.

Finalmente, os trinta artigos da Declaração Universal dos Direitos Humanos podem ser a referência para a estrutura curricular de uma escola durante todo o ano letivo, em todas as séries. Assim, o aprendizado das operações matemáticas mais elementares, os processos de alfabetização, o estudo das plantas, o conhecimento da realidade do próprio bairro, seriam utilizados para levar alunos e alunas a conhecer e a experienciar os conteúdos específicos dos artigos desse documento, visando sua formação ética e a transformação do mundo em que vivem. A importância: do lazer; do direito à diversidade de pensamento e de crença; do respeito nas relaçôes interpessoais; do direito a moradia, a saúde e a educação são exemplos de temáticas que envolvem a construção da cidadania e que poderiam ser o eixo vertebrador do currículo escolar. 
Como desenvolver o currículo a partir dos pressupostos discutidos até o momento? Incorporando os referenciais de teorias da complexidade, da transversalidade, do construtivismo e do protagonismo dos estudantes na produção de novos conhecimentos. Para isso, precisamos buscar novas metáforas para representar a organização curricular, como a do rizoma ou a das redes neurais, e assumir a pedagogia de projetos como um caminho possível.

\section{Os projetos como estratégia pedagógica}

A palavra projeto deriva do latim projectus e significa algo como um jato lançado para frente. No caso do ser humano, ao ser lançado no mundo, ao nascer, ele vai se constituindo como pessoa por meio do "desenvolvimento da capacidade de antecipar açôes, de eleger, continuamente, metas a partir de um quadro de valores historicamente situado e de lançar-se em busca das mesmas." (Machado, 2000, p.2). Para compreender seu significado geral, o autor aponta três características fundamentais de um projeto:

- a referência ao futuro;

- a abertura para o novo;

- a ação a ser realizada pelo sujeito que projeta.

Projetos podem ser compreendidos também como estratégias de ação e possuem três características constitutivas (Rué, 2002, p.96):

- a intenção de transformação do real;

- uma representação prévia do sentido dessa transformação (que orienta e dá fundamento à ação);

- uma ação em função de um princípio de realidade (atendendo às condiçôes reais decorrentes da observação, do contexto da ação e das experiências acumuladas em situaçôes análogas).

Com os projetos pretende-se (Hernández,1998, p.73):

- estabelecer as formas de "pensamento atual como problema antropológico e histórico";

- dar um sentido ao conhecimento baseado na busca de relaçôes entre os fenômenos naturais, sociais e pessoais, ajudando-nos a compreender melhor a complexidade do mundo em que vivemos;

- planejar estratégias para abordar e pesquisar problemas que vão além da compartimentalização disciplinar.

Se pensarmos a organização escolar a partir de tais idéias, podemos falar de uma pedagogia de projetos. Ou seja, podemos acreditar que um caminho possível para trabalhar os processos de ensino e de aprendizagem, no âmbito das instituiçốes escolares, pode ser através de projetos, concebidos como estratégias para a construção dos conhecimentos. 
De acordo com Hernández (1998, p.72), citando Bruner, os projetos podem ser uma peça central do que seria a filosofia construtivista na sala de aula. "Aprender a pensar criticamente requer dar significado à informação, analisála, sintetizá-la, planejar ações, resolver problemas, criar novos materiais ou idéias,... e envolver-se mais na tarefa de aprendizagem".

Assim, enfatizando que nem todas as propostas de projeto são coerentes com as características da transversalidade aqui assumida, pois podem ser trabalhados da maneira mais tradicional possível, apresentaremos a seguir um caminho prático para a inserção dos temas transversais no planejamento pedagógico, por meio da estratégia de projetos.

\section{O conhecimento como rede e os princípios de transversalidade}

Na perspectiva de articulação entre transversalidade e interdisciplinaridade que adotamos em nosso trabalho, as ligaçôes entre os diferentes conhecimentos não ocorrem por meio de cruzamentos pontuais entre as temáticas abordadas, pois assim manter-se-ia a fragmentação dos conhecimentos. A novidade está em buscar a organização curricular na estratégia pedagógica dos projetos, assumindo que o avanço na compreensão da natureza, da cultura e da vida humana está nas ligações que podemos estabelecer entre os mais diversos tipos de conhecimento: científicos; populares; disciplinares; não-disciplinares; cotidianos; acadêmicos; físicos; sociais, etc. Ou seja, o "segredo" está nas relações, nos infinitos caminhos que permitem ligar os conhecimentos uns aos outros.

$\mathrm{Na}$ escola, isso se traduz em projetos que tenham um ponto de partida, mas cujo ponto de chegada é incerto, indeterminado, pois está aberto aos eventos aleatórios que perpassam o processo de seu desenvolvimento, ou seja, em projetos que reconheçam o papel de autoria de alunos e alunas, mas que reforcem a importância da intencionalidade do trabalho docente para a instrução e a formação ética. Esse processo deve ocorrer em uma perspectiva que reconheça a importância das especializaçôes dos professores de Matemática, de Língua Portuguesa, de Ciências, etc., e que estes assumam o papel dessas áreas disciplinares e suas infinitas interligações possíveis como "meio" para o objetivo maior de construção da cidadania.

Daí a importância de buscar novas metáforas iluminadoras para auxiliar na compreensão das relações existentes entre o ser humano e o mundo natural e cultural. A metáfora que procura reproduzir a organização das redes neurais e compreender os conhecimentos como uma rede de significados é um bom caminho nesse sentido.

Embora já estivesse empregando a metáfora da "rede" há um bom tempo nos projetos pedagógicos e curriculares que desenvolvo, encontrei no trabalho 
de Machado (1995) e em suas citações sobre as idéias de Michel Serres e Pierre Lévy a fundamentação teórica que me ajudou a compreender e transformar as açôes práticas que vinha desenvolvendo.

Nesse sentido, a idéia de rede é entendida como metáfora para a representação do conhecimento e possui, como material constitutivo de sua teia de relações, as significaçôes que Machado (1995, p.138), de forma resumida, afirma:

- compreender é apreender o significado;

- apreender o significado de um objeto ou de um acontecimento é vê-lo em suas relaçôes com outros objetos ou acontecimentos;

- os significados constituem, pois, feixes de relaçóes;

- as relaçôes entretecem-se, articulam-se em teias, em redes, construídas social e individualmente, e em permanente estado de atualização;

- em ambos os níveis - individual e social - a idéia de conhecer assemelha-se à de enredar.

Uma outra característica da rede é que ela

contrapõe-se diretamente à idéia de cadeia, de encadeamento lógico, de ordenação necessária, de linearidade na construção do conhecimento, com as determinaçóes pedagógicas relacionadas com os pré-requisitos, as seriações, os planejamentos e as avaliaçóes (Machado, 1995, p.140).

Complementando os pressupostos que nos ajudam a compreender a metáfora da rede, Machado recorre à metáfora do hipertexto, proposta por Pierre Levy (1993, p.25), quando afirma que o hipertexto é talvez uma metáfora válida para todas as esferas da realidade em que significaçóes estejam em jogo. Aponta, então, os seis princípios que Levy chama de conformadores do hipertexto e que podem ser transportados para caracterizar a metáfora do conhecimento como rede.

- Principio de metamorfose - a rede está em constante construção e transformação e, a cada instante, podemse alterar os feixes que compõem os nós, atualizando o desenho da rede.

- Principio de heterogeneidade - os nós e as conexões de uma rede são heterogêneos, significando que existe uma multiplicidade de possibilidades de interligação entre eles. Apenas como exemplo, nessas ligações, que podem ser lógicas, afetivas, analógicas, sensoriais, multimodais, multimídias, podem ser utilizados sons, imagens, palavras e muitas outras linguagens.

- Principio de multiplicidade e de encaixe das escalas - a rede organiza-se de modo "fractal", ou seja, qualquer nó ou conexão, quando analisado, pode 
revelar-se como sendo composto por toda uma rede, e assim por diante, indefinidamente (Levy, 1993, p.25).

- Principio de exterioridade - a rede é permanentemente aberta ao exterior, à adição de novos elementos, a conexôes com outras redes.

- Principio de topologia - na rede, o curso dos acontecimentos é uma questão de topologia, de caminhos.

- Princípio de mobilidade dos centros - a rede não tem centro, ou pode ter vários centros que trazem ao redor de si pequenas ramificaçôes.

O desafio passou a ser traduzir todos esses princípios em uma estratégia pedagógica de projeto que permitisse trabalhar a transversalidade na educação, articulada com a interdisciplinaridade. Trabalhando nessa perspectiva, a Escola Comunitária de Campinas, sob minha supervisão, passou a orientar seu currículo a partir da estratégia de projetos, utilizando a metáfora das redes neurais.

Mais importante ainda, articulado com essa perspectiva, trouxe para o cotidiano das salas de aula a preocupação com a educação em valores, com a busca de solução para os problemas sociais e a tentativa de ligação dos conteúdos científicos e culturais com a vida das pessoas, definindo que os temas dos projetos deveriam estar relacionados com a Declaração Universal dos Direitos Humanos.

\section{Alguns resultados...}

Pelo pouco espaço disponível em um artigo, não podemos trazer com detathes a riqueza qualitativa dos projetos desenvolvidos nessa escola e os registros feitos pelos docentes, que foram publicados pela própria escola e socializados com os pais em $2004 \mathrm{em}$ um texto intitulado "O trabalho com projetos e os direitos humanos: um espaço para refletir e vivenciar valores". Esse trabalho contou com a participação de todos os professores dos Ciclos I e II da escola.

Apenas para demonstrar os resultados com os estudantes da escola, decidimos promover uma coleta de dados no final de 2003, comparando as representaçôes que aquelas crianças tinham sobre temas de natureza ética com as representações de crianças de outras duas escolas: a) uma escola privada, católica, localizada no município de São Paulo; b) uma escola pública, localizada na cidade de Três Corações, em Minas Gerais.

Em uma primeira questão, perguntamos às crianças, de 7 a 10 anos de idade:

A escola criou um jornal e esta semana é sua responsabilidade definir qual será o tema principal que será discutido nas páginas do jornal. Qual seria esse tema? 
A intenção dessa pergunta era verificar que tipo de conteúdo os sujeitos apresentavam de maneira espontânea, ao serem solicitados a elaborar uma matéria para um jornal escolar. Pensamos que se as temáticas propostas fossem de natureza ética, era provável que tais sujeitos tivessem tais conteúdos como centrais em sua identidade. Ao contrário, se as respostas fossem de natureza nãoética, aumentaria a probabilidade de que suas preocupaçôes cotidianas estivessem mais voltadas para assuntos de natureza pessoal.

Os critérios empregados para classificar as respostas foram: respostas éticas e respostas não-éticas. Por resposta ética foram definidas aquelas que demonstravam uma consciência referenciada nos interesses coletivos; na preocupação com as outras pessoas; e nos valores virtuosos valorizados por nossa cultura (Araújo, 1999, p.99). Ou seja, as respostas éticas eram aquelas vinculadas a princípios de justiça, de igualdade, de generosidade, de altruísmo, de responsabilidade e de preocupação para com o coletivo. As respostas não-éticas eram aquelas cujo conteúdo não se enquadrava no que foi definido como ético. Eram de um domínio mais pessoal, o que não significava que fossem respostas imorais, e sim, que não eram éticas.

Os dados encontrados, com 262 crianças das três escolas, foram:

Tabela |. Representaçōes infantis espontâneas sobre conteúdos de natureza ética

\begin{tabular}{|l|c|c|c|c|c|}
\hline \multirow{2}{*}{ Escola } & \multicolumn{4}{|c|}{ Respostas } \\
\cline { 2 - 5 } & \multicolumn{2}{|c|}{ Ética } & \multicolumn{2}{c|}{ Não-Ética } & \multirow{2}{*}{ Total } \\
\cline { 2 - 5 } & $\mathrm{n}$ & $\%$ & $\mathrm{n}$ & $\%$ & \\
\hline $\begin{array}{l}\text { Escola Comunitária } \\
\text { (Campinas) }\end{array}$ & 71 & $80 \%$ & 18 & $20 \%$ & 89 \\
\hline $\begin{array}{l}\text { Escola Privada } \\
\text { (São Paulo) }\end{array}$ & 57 & $64 \%$ & 32 & $36 \%$ & 89 \\
\hline $\begin{array}{l}\text { Escola Pública } \\
\text { (Três Corações) }\end{array}$ & 170 & $65 \%$ & 92 & $35 \%$ & 262 \\
\hline Totais & 42 & $50 \%$ & $50 \%$ & 84 \\
\hline
\end{tabular}

Os dados da tabela acima demonstram como, na representação espontânea, as crianças da Escola Comunitária de Campinas apresentam uma maior preocupação ética e social. Essa categoria foi empregada por $80 \%$ dessas crianças, enquanto $64 \%$ das crianças da outra escola privada e $50 \%$ de crianças da escola pública apresentaram a mesma preocupação. 
Em uma outra questão, apresentamos às crianças uma "tirinha", contendo o desenho de uma casa pobre ao lado de uma casa rica, perguntando tanto como representavam as causas para aquela situação, como as soluçóes para resolvê-la. Nesse caso, estávamos interessados não apenas na representação das crianças sobre uma temática ético-social, mas no trabalho com Resolução de Conflitos. Daí colocar na "tirinha" o antes e o depois, as causas e as soluções para o conflito apresentado.

No tocante à categorização dos dados, optamos por duas categorias de análise: a) respostas sócio-políticas, em que os sujeitos apontavam uma percepção social e política para explicar por que existiam casas tão diferentes convivendo lado a lado, e para pensar nas soluçôes para a questão; e respostas de outra natureza, em que apontavam explicaçóes simplificadas para o conflito, ou religiosas, ou "mágicas". Por exemplo, neste último caso, principalmente os sujeitos da escola pública responderam que a causa era que Deus tinha feito assim e a solução era o rico dar uma casa para o pobre.

A tirinha apresentada era a seguinte (figura1):

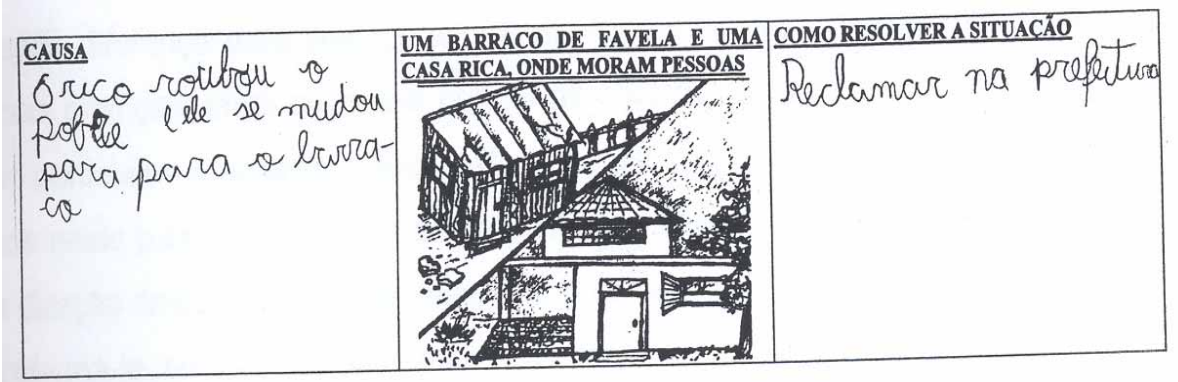

Os resultados encontrados foram:

Tabela 2. Percepção sócio-política sobre desigualdades sociais

\begin{tabular}{|c|c|c|c|c|c|c|c|c|c|}
\hline \multirow{3}{*}{ Escola } & \multicolumn{4}{|c|}{ Causa } & \multicolumn{4}{|c|}{ Solução } & \multirow{3}{*}{ Total } \\
\hline & \multicolumn{2}{|c|}{ Sócio-política } & \multicolumn{2}{|c|}{ Outra } & \multicolumn{2}{|c|}{ Sócio-política } & \multicolumn{2}{|c|}{ Outra } & \\
\hline & $\mathrm{n}$ & $\%$ & $\mathrm{n}$ & $\%$ & $\mathrm{n}$ & $\%$ & $\mathrm{n}$ & $\%$ & \\
\hline $\begin{array}{l}\text { Escola Comunitária } \\
\text { (Campinas) }\end{array}$ & 47 & $54 \%$ & 40 & $46 \%$ & 24 & $28 \%$ & 63 & $72 \%$ & 87 \\
\hline $\begin{array}{l}\text { Escola Privada } \\
\text { (São Paulo) }\end{array}$ & 15 & $19 \%$ & 62 & $81 \%$ & 17 & $22 \%$ & 60 & $78 \%$ & 77 \\
\hline $\begin{array}{l}\text { Escola Pública } \\
\text { (Três Corações) }\end{array}$ & 5 & $6 \%$ & 84 & $94 \%$ & 6 & $7 \%$ & 83 & $93 \%$ & 89 \\
\hline Totais & 67 & $26 \%$ & 186 & $74 \%$ & 47 & $19 \%$ & 206 & $81 \%$ & 253 \\
\hline
\end{tabular}


Percebe-se, novamente, como as crianças da Escola Comunitária de Campinas apresentaram um pensamento mais crítico diante de uma problemática social como a que foi proposta. No caso, chamou atenção a grande diferença em relação aos alunos da escola pública. Praticamente todas essas crianças, tanto na causa quanto na solução, deram respostas em que revelavam não perceberem a natureza sócio-política das diferenças abissais entre pobres e ricos neste país. Quase todas as propostas de solução para o problema iam na direção de que os ricos deveriam dar uma casa melhor ao pobre ou ajudar a reformála, ou ainda fazer caridade para com eles.

Enfim, os dados apresentados são apenas alguns indícios obtidos de como as crianças que estavam participando de um trabalho sistematizado de educação em valores éticos e democráticos, por meio de projetos, e que tinham os direitos humanos como referência, demonstraram uma maior consciência ética e sócio-política. Isso mostra a importância desse tipo de trabalho para que a educação atinja um dos seus principais objetivos, que é a formação moral de seus alunos e alunas.

\section{Considerações fınais}

Com esse trabalho, penso ter conseguido construir, com todos os docentes e estudantes, que foram os verdadeiros atores e atrizes do processo, formas diferentes de reorganizar os espaços, os tempos e as relaçóes escolares, de modo a construir um projeto educativo coerente com os objetivos de democracia e de justiça social. A inserção de temáticas transversais na organização curricular das escolas pode propiciar uma forma eficiente de ação social com o objetivo de levar alunos e alunas a pautarem seus pensamentos e ações em valores éticos.

No fundo, o que tentamos com propostas como esta é construir um tipo de educação em valores que fuja das formas tradicionais prescritivas e autoritárias, defendidas por igrejas, famílias e também por muitos profissionais da educação. Esse tipo de educação moral tradicional, que de fato pode ser chamada de "educação de valores" previamente determinados, não contribui para a construção do que chamamos de personalidades morais autônomas, pois não considera a complexidade da natureza psicológica do ser humano e está a serviço de modelos autoritários que reforçam e "naturalizam", nas mentes infantis, as injustiças e as desigualdades sociais.

Romper com essa educação autoritária, em busca de modelos dialógicos pautados em valores de democracia, justiça, solidariedade e outros mais (como aqueles presentes na Declaração Universal dos Direitos Humanos) pressupõe introduzir no dia-a-dia das escolas e das salas de aula a preocupação com valores socialmente desejáveis. Esse trabalho, no entanto, precisa ser sistematizado 
e intencional, de forma a ser "naturalizado" entre todos os membros da comunidade escolar. Isso fará com que a educação em valores deixe de ser algo pontual e esporádico, que ocorre em aulas ou em momentos específicos, e passe a ser um movimento imbricado, "natural", na rotina cotidiana das escolas.

\section{Referências bibliográfıcas}

ARAUJO, U. F. Conto de escola: a vergon ha como um regulador moral. São Paulo: Moderna e Editora da Unicamp, 1999.

HERNÁNDEZ, F;; VENTURA, M. A organização do curriculo por projetos. Porto Alegre: Artes Médicas, 1998.

LEVY, P. As tecnologias da inteligência: o futuro do pensamento na era da informática. São Paulo: Editora 34, 1993.

MACHADO, N. Epistemologia e Didática: as concepçôes de conhecimento e inteligência e a prática docente. São Paulo: Cortez, 1995.

MACHADO, N. Educação: projetos e valores. São Paulo: Escrituras, 2000.

MORENO, M. Temas transversais: um ensino voltado para o futuro. In: BUSQUETS, M.D. et al. Temastransversais em educação. São Paulo: Ática, 1997.

RUÉ, J. Qué enseñary por qué: elaboración y desarrollo de proyectos de formación. Barcelona: Paidós, 2002.

Recebido em 10 de abrilde 2007 e aprovado em 21 de setembro de 2007. 